\title{
Maintaining the status quo: the nature and role of policy stakeholders' perceptions of event value
}

\author{
Martin Wallstam
}

Department of Economics, Geography, Law and Tourism, Mid Sweden University, Ostersund, Sweden

\begin{abstract}
Purpose - This paper explores event value from the perspective of policy stakeholders and discusses potential implications of this stakeholder group's perceptions of value on event policy, event evaluation and the public discourse on the value of events.

Design/methodology/approach - A thematic analysis is employed to analyze nine interviews from respondents who were deemed to fit the study criteria in the case of Östersund, Sweden.

Findings - Findings indicate that value is portrayed in largely economic terms or in proxy-economic terms even though the respondents expressed awareness and concern for social aspects of value. Moreover, the article highlights the glaring omission of the relationship between policy stakeholders and the nature of evaluation efforts in the industry and academia.

Originality/value - The article addresses a still somewhat unexplored dynamics between influential policy stakeholders and how events are regarded in terms of their potential contribution to community development. To what degree does the way the events sector and the general public value events emanate from the way events have been instrumentalized in policy throughout history?
\end{abstract}

Keywords Event evaluation, Event management, Event Policy, Event portfolio, Event value

Paper type Research paper

\section{Introduction}

Although often hailed as panaceas for a multitude of societal ailments, the potential of events to foster change is not always realized. Indeed, perhaps the greatest weakness of the events sector is the lack of common understanding among different stakeholders about what precisely events are expected to contribute. In other words, the usefulness of an event differs depending on what type of stakeholder you are and the specific set of goals you have (Van Niekerk, 2016). Most events (but especially large-scale or hallmark ones) are promoted by a multitude of stakeholders who often have widely diverging interests (Todd et al., 2017). Synergizing these interests would lower financial and social costs, thereby also optimizing leveraging efforts. Not least so in the case of policy stakeholders who steer the direction of event strategies (see Table 1).

This paper employs the term "policy stakeholder" to distinguish it from the otherwise commonly used "primary stakeholder" (Reid, 2006; Getz and Andersson, 2010; Todd et al., 2017). The term primary stakeholder is often found in research about the stakeholders of events, as opposed to the stakeholders of entire event portfolios, as in this article. Therefore, policy stakeholder will here denote any person or organization that holds direct influence over the policymaking process surrounding multiple events. These include regional and municipal

(C) Martin Wallstam. Published by Emerald Publishing Limited. This article is published under the Creative Commons Attribution (CC BY 4.0) licence. Anyone may reproduce, distribute, translate and create derivative works of this article (for both commercial and non-commercial purposes), subject to full attribution to the original publication and authors. The full terms of this licence may be seen at http:// creativecommons.org/licences/by/4.0/legalcode

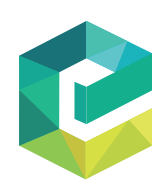

International Journal of Event and Festival Management Vol. 13 No. 2, 2022 Emerald Publishing Limite 1758-2954 DOI 10.1108/IJEFM-06-2021-0053 
IJEFM

13,2

220

government officials, DMO (Destination Management Organization) representatives as well as organizers of large-scale or hallmark events who are consulted on event matters and are in regular contact with regional and local government. In terms of stakeholder theory, these are dominant stakeholders that hold all three stakeholder saliency attributes of Power, Legitimacy and Urgency (PLU) in relation to the local event policy (Mitchell et al., 1997).

Underlying any stakeholder's behavior is their perception of an event's value, shaped by the stakeholder's own specific frame of reference. The concept of value has been explored from several theoretical perspectives (Lundberg et al., 2017). Some well-known examples are found in the philosophical, sociological and economic conceptions of value. In philosophy, the study of value is known as axiology, further subdivided into ethics (moral values) and aesthetics (values pertaining to beauty and taste) (Hart, 1971). In economics, value is perceived through the "theory of value," which deals with "value-in-exchange" of commodities, goods and services (Deane, 1978). In sociology and anthropology, value is observed as different forms of capital meaning the social and symbolic resources that can be used to further one's standing in a society or within a specific social group (Bourdieu, 1986).

In order to be able to move toward more proactive and inclusive policy models, we must first answer questions about how and why policy stakeholders reason the way they do about events. Having answers to such questions allows us to explore the various implications with regard to the wider base of passive stakeholders (such as the general public), who might not hold sway over event policy but nonetheless are affected by it.

\section{Aim}

This paper aims to explore how policy stakeholders attribute value to events and how this might impact event evaluation and event policy, with the hope of better understanding the role of this stakeholder group in shaping the public discourse about events and what they are worth.

To address this aim, the paper will attempt to fulfill the following research objectives:

Research Objective 1. Outline the principal theories that inform how event value is perceived by policy stakeholders.

Research Objective 2. Identify the core themes that emerge when policy stakeholders themselves discuss value in relation to events.

Research Objective 3. Discuss how the views on value expressed by the policy stakeholders might influence event evaluation and event policy and what consequences there might be from this dynamic on the public discourse on events.

\section{Literature review}

The value of events

The academic literature about the value of events for communities ranges from studies about their importance as a central element in community celebration (Crespi-Vallbona and Richards, 2007; Delgado, 2017) and events as a means to promote the destination brand (Richards, 2017) to a wealth of research on the revenue-generating potential of events for communities. The economic performance of the organizer and the income generated for the local community are both dependent on investments related to the staging of the event as well as the money spent by event visitors, both inside the event and in the community. The latter is an event's bottom-line economic worth (Dobson and Goddard, 2011; Davies et al., 2013; 
Kwiatkowski, 2016). Whereas organizers do not differentiate between money spent by different types of visitors, income for the community on a macro level is closely tied to the number of tourists that attend an event as this represents new capital for the local economy (Dwyer et al., 2000; Dwyer and Forsyth, 2017). Events can also act as catalysts for arts, businesses and other events as they provide spaces where creative and entrepreneurial ideas are exposed to new audiences. This incubation function encompasses things often considered part of the event such as food stands, small side shows, sponsor spaces, educational seminars and more (Sundbo, 2004; Jones and Ponzini, 2020). While research has identified social value abound, Djaballah et al. (2015) found that local governments tend to be unaware of these social benefits and leveraging opportunities connected to events and often leave efforts to capitalize on such opportunities to the organizers themselves.

\section{Underlying perspectives on event value: philosophy}

The philosophical view on value encompasses numerous discourses about value, but perhaps the most pervasive in an events context is the axiological perspective. Broadly speaking, axiology is concerned with the nature of good and bad and whether the value of an object is subjective or objective in nature (Hart, 1971). As such, axiology permeates all research on event evaluation as evaluation at its most basic is the pursuit of establishing if an event is "good" or "bad." However, the moral judgment of good and bad is based on the assumption that events are supposed to achieve something.

A central dichotomy found in the philosophical discourse on value is therefore one pitting intrinsic against instrumental value. In the context of events, this conflict is ever present (McFee, 2012). Whereas the intrinsic value of an event would be that it holds value "in-and-of itself," instrumentalism sees value based on the potential of the event to contribute to achieving tangible goals. Getz (2018) suggests that, although cultural events sometimes are portrayed as intrinsically valuable, the instrumentalist view of events is dominant as they often are viewed as a means to achieve monetary goals.

\section{Underlying perspectives on event value: sociology}

In sociology, capital theory has long informed how individuals and groups create and transfer value. Bourdieu (1986) outlines three main forms of capital that include economic, social and cultural capital. Capital, according to Bourdieu, is defined as all assets that can be put to productive use to advance one's position in society. Whereas social capital refers to assets in the form of relationships between individuals and groups (Portes, 1998), cultural capital denotes all desirable symbolic assets (such as knowledge about or the possession of cultural goods) that an individual or group uses to gain social standing (Kisida et al., 2014).

Social capital is the most prominently featured form of noneconomic capital in events research (Arcodia and Whitford, 2007; Getz and Page, 2016; Jamieson, 2014; Molitor et al., 2011; Moscardo, 2007; Sharpley and Stone, 2012; Sherry et al., 2011; Ziółkowska, 2020). Cultural capital, meanwhile, is often merely mentioned in passing or in conjunction with social capital (Getz and Page, 2016).

However, research on capital theory and events often points out one general weakness of the concept. Although there is social potential abound, the awareness of this potential, and more importantly, the ability to understand, measure and leverage it, has been seriously lacking throughout the modern history of events (Chalip, 2004, 2006; Sharpley and Stone, 2012; Rogerson et al., 2019; Wallstam et al., 2018).

\section{Underlying perspectives on event value: economics}

Perhaps the most familiar theories around value are found in the marketing and microeconomic literature, where the last two decades have been dominated the Service stakeholders' perceptions of event value 
IJEFM

13,2

Dominant Logic (Vargo and Lusch, 2004), which replaced older marketing and management paradigms focusing on commodities and goods. Setting paradigms aside, Zeithaml (1988, p. 14) provides an overarching definition of value from a consumption perspective:

... perceived value is the consumer's overall assessment of the utility of a product based on perceptions of what is received and what is given.

In other words, value is subjective and always entails salient "give" and "get" components where what has been obtained is put into relation to its cost.

Event marketing literature frames the value of events as experiences that are bought based on the individual's perception of the quality of the offer that the event represents in relation to the investment and efforts made by the consumer to partake in the event (Martensen and Grønholdt, 2008). The consumer's perception of quality can then be subdivided into those factors that create satisfaction, and those that help to avoid dissatisfaction. The latter were originally dubbed "hygiene factors" by Herzberg (1959) in his seminal work on workplace motivation. The concept of hygiene factors has since been widely adopted into consumer satisfaction literature (notably by Kano et al., 1984, as "must-be quality") and eventually into literature on visitor satisfaction at events (e.g. Crompton, 2003) as a way of conceptualizing the necessary components of perceived quality in an event product. This concept of multiple factor quality can be used not just to understand the event visitor's perception of quality and value, but also the perceptions of other stakeholders.

Efforts have been made to capture the perceived value of events in economic terms. "Usevalue" refers to visitors' willingness to pay for an event in terms of entrance fees and other costs associated with attendance. Conversely, the "nonuse" value of an event is how much community members who do not attend an event are willing to pay for the existence of it because of the indirect value it has for them in terms of their sense of pride or for the value they perceive it to have for other community members (Andersson and Armbrecht, 2014; Andersson et al., 2017a, b). Arguably, nonuse value represents a form of social value as it demonstrates the willingness for taxpayers to keep even economically unviable events afloat.

\section{The role of policy stakeholders in shaping event value}

The most commonly held perspectives relating to event value originate from a narrow set of stakeholders, namely those who are involved in forming policy directives (Wood, 2008). Such stakeholders are often able to significantly influence how value is perceived by the wider community in debates about the event value, especially in the case of major and mega events (Armstrong et al., 2011; Zimbalist, 2010).

Stakeholder Theory is used as a means to study stakeholder roles and relationships that underlie such tendencies. It highlights the importance of identifying and accommodating for the various stakeholders of an organization, suggesting that this should be the first step of any strategic action (Mitchell et al., 1997). Strategic stakeholder management has gained increased attention in the last 20 years, and the study of event stakeholders on the level of the individual event has come some way since then (Reid, 2006; Getz and Andersson, 2010; Todd et al., 2017; Van Niekerk and Getz, 2019). However, the study of stakeholders of entire event portfolios on the destination level remains underresearched (Ziakas and Getz, 2020).

Policy stakeholder perceptions of value need to be studied because of the role they play in event evaluations. An appraisal of value does not occur in a vacuum but is shaped by the reference points that the evaluator uses to gauge value (Holbrook and Corfman, 1985; Getz, 2018). These reference points in turn decide the standards by which an event will be judged. Although efforts have been made, rarely are multiple stakeholders truly given enough room in the evaluation process (Goldblatt, 2011). Instead, those who commission evaluations often impose evaluation benchmarks and KPIs (Key Performance Indicators) as suits their perspective (Getz, 2018). 
Getz and Andersson (2010) conducted a comparative study of stakeholder dependencies in Sweden, Norway, Scotland and Australia. Their findings indicated that the same general tendencies in stakeholder relationships can be found across the economic North. Specifically, they found venue providers and local government to be the stakeholder groups to which other stakeholder groups form the strongest dependencies. With a high degree of influence, these powerful stakeholders are likely to be able to impose their conception of value on other stakeholders such as event visitors or small organizers (who do not own the venues they use), but are compelled to appease the powerful stakeholders or at the very least take part in evaluations framed according to their views on value.

Literature on event evaluation distinguishes assessment (limited, one-dimensional focus) from evaluation (comprehensive, multidimensional) (Getz, 2018). However, assessments are often passed off as evaluations in both industry and academia (Brown et al., 2015). This tendency is symptomatic of the lack of common understanding of sound evaluation practice. Influential stakeholders wishing to gain support for an event are often able to do so by passing off success in one domain (often economic) as complete success (O'Sullivan et al., 2009). Awareness of the perspectives that inform evaluation praxis, especially in the nonacademic settings (where transparency varies), is arguably one way of reducing malpractice and the cynical misuse of events as mere policy instruments.

The four-field model of event value provided by Lundberg et al. (2017) illustrates value according on intrinsic/extrinsic and individual/society axes (Figure 1). While providing a good overview of the categories of event value, this model stops short of showing the process by which policy stakeholders conceptualize event value.

\section{Methodology}

This study is built on a thematic analysis of nine semistructured interviews of policy stakeholders in and around Ostersund municipality, Northern Sweden. Located in an outdoor recreation-oriented region heavily dependent on tourism (approximately 10m guest nights per year), but lacking its own mountains, Östersund itself is usually dependent on resorts nearby by drawing in their transiting visitors (JHT, 2021). The city itself was recently rebranded from "The Winter City" to "The Östersund Pulse" in an effort to diversify the brand from a seasonally dependent winter destination to a year-round hot spot filled with opportunity for outdoor recreation and in particular, an events portfolio containing 188 events that provides entertainment in what is usually the low season for the region; meaning late spring, to some degree summer and autumn (Ostersundspulsen, 2021).

As already mentioned, the definition of a "policy stakeholder" is in this study any person or entity that is involved in strategic decision-making with regard to events or directly involved in the production of large-scale events. The latter are included because their influence over event-related policy is generally speaking significant (Getz and Andersson, 2010).

\section{Sampling}

Purposeful criterion-based sampling was used to identify suitable research subjects. Purposeful sampling is relevant in studies that require "the identification and selection of information-rich cases related to the phenomenon of interest" (Palinkas et al., 2015, p. 533). First of all, the proposed respondents must be active in the same administrative region. In this way, all respondents should have the same background knowledge about which events take place in the region as well as what the historic development of the region has been. In line with the social constructionist perspective (detailed later), putting interview subjects in the context of the systems of practice they belong to and the social environments that follow grants the study an insight into the processes that form value perception in the individual (Crotty, 1998). The main venues in Östersund are owned by either the municipality or by the organizers 
IJEFM

13,2

\section{4}

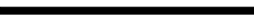

Figure 1.

A four-dimensional approach to event values

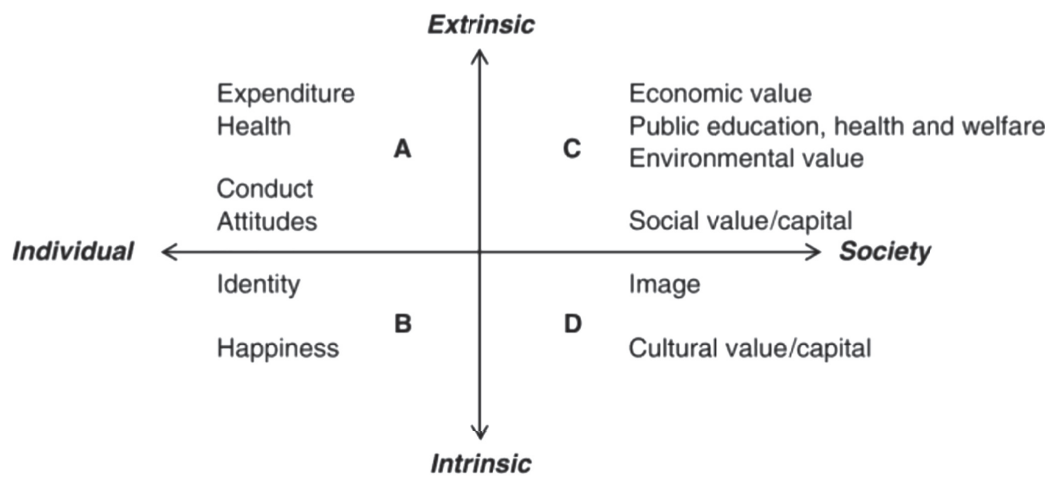

Source(s): Lundberg et al. (2017)

behind the events that are staged in them. Hence, by sampling the organizers of the hallmark events in Östersund, the study is able to also capture venue owners, a critical group according to Getz and Andersson (2010).

Twelve interview requests were sent out from which nine prospective respondents agreed to be interviewed. The criteria used to select potential respondents were as follows:

(1) The interviewee has to have a job description that refers to event or destination development in some manner.

(2) The interviewee has to have an upper managerial or decision-making role within their organization.

(3) The interviewee has to have at least 1-year experience in their current position.

(4) Both public and private respondents have to be chosen since, as earlier mentioned, both hold sway over the direction of municipal events policies.

Table 1 shows the final selection of interviewees used in this study, as well as their professional roles in relation to events.

\begin{tabular}{|c|c|}
\hline $\begin{array}{l}\text { Interviewee } \\
\text { reference \# }\end{array}$ & Interviewee role \\
\hline 1 & $\begin{array}{l}\text { The tourism strategist at the municipality. Responsible for questions related to } \\
\text { tourism and events }\end{array}$ \\
\hline 2 & $\begin{array}{l}\text { CEO, organizer of one of the biggest youth sports events in the region and also in } \\
\text { Sweden }\end{array}$ \\
\hline 3 & Head of the board of the hallmark music festival of Östersund \\
\hline 4 & $\begin{array}{l}\text { Local events champion that has been involved in a number of major events locally } \\
\text { throughout the years, has served on numerous boards from winter sports to music } \\
\text { festivals }\end{array}$ \\
\hline 5 & $\begin{array}{l}\text { Owner and organizer at one of the main cultural venues in Östersund, also involved in } \\
\text { a number of local festivals and smaller cultural events in the municipality }\end{array}$ \\
\hline 6 & Director at the region-wide Destination Management Organization \\
\hline 7 & Events manager for a local top-tier sports team \\
\hline 8 & President of the organizational committee of an annual winter sports event \\
\hline 9 & Developer/strategist at the city's destination company/destination brand \\
\hline
\end{tabular}




\section{Data collection}

By using semistructured interviews, the aim was to explore each interviewee's concept of value and especially what aspects these individuals consider to be valuable in events. It was possible to explore their assumptions and prejudices about the value concept by asking about their general perspective on events and value. This was followed by probing questions about their personal experiences in event setting and how they have seen event value manifested. In other words, what first-hand experiences and examples did they have of events providing value for the community?

The interviews ranged from $35 \mathrm{~min}$ to $1 \mathrm{~h} 14 \mathrm{~min}$. They were all conducted in person and using a recorder. Although there only are a limited number of persons that could be considered "policy stakeholders" in the study area, great care was taken to maximize anonymity without sacrificing the richness of interview material and the integrity of the data. As there currently is no one-size-fits-all approach to anonymizing data, compromises are always made based on the content of interview transcripts as well as the social and political context of the problem being studied (Saunders et al., 2015).

\section{Methodological and epistemological stance}

As the specific idea of studying how policy stakeholders perceive event value is novel, it warrants an exploratory approach. An exploratory approach allows potential themes, tendencies and patterns concerning event value to be identified to then be further tested in future research. The interviews make it possible to scrutinize several members from the same stakeholder group to distinguish sentiments about value that are coconstructed within the group from those that are formed independently of the respondents' shared group culture.

Social constructionism is the epistemological foundation that informs the exploratory approach of this paper. Social constructionism posits that individuals and groups allocate meaning to phenomena and subsequently share this meaning, institutionalize it and eventually consolidate it as tradition (Andrews, 2012). Hence, the shared meaning attributed to the phenomenon of event value among policy stakeholders should be identifiable through the analysis of the nine interviews that were conducted.

\section{Analysis}

The data was coded manually, based on the open coding process outlined in Strauss and Corbin (1997). Open coding involves conceptualizing all the incidents in a transcript. An "incident" refers to any content that may hold some meaning with regard to the research problem. Concepts are created and continually compared to merge or create new concepts as the researcher works through the data. In other words, each of the interview transcripts was combed through for references to how the interviewees conceptualize events, how they define "value," challenges to creating event value and how these challenges can be addressed. Once identified, such a reference was coded according to what view of value it expressed. Finally, this information was coded into wider themes as they emerged (Silverman, 2010).

To effectively identify shared meanings, the interview material was then processed using thematic analysis. As a subset of social constructionism, thematic analysis essentially provides a window into how reality is coconstructed between different actors in society. It recognizes that any subject matter related to the dynamics between people must be contextualized and dealt with on a case-by-case basis (Filia et al., 2018). Braun and Clarke (2006) outline a step-by-step procedure of how to undertake thematic analyses. It includes (1) becoming familiar with the data, (2) generating initial codes, (3) identifying themes, (4) reviewing the identified themes, (5) defining and labeling each theme, (6) coding the identified themes and finally, (7) producing a report based on the themes. These steps were closely followed in the analysis of the interview transcripts. stakeholders' perceptions of event value 
IJEFM

13,2

\section{Themes}

The thematic analysis of the interview transcripts generated five clearly discernible themes that reflect how events are considered valuable by policy stakeholders. Although the interviewees diverged on some issues, the purpose of this paper is primarily to explore where their attitudes converge.

The following themes emerged from the interviews:

(1) Economic value as a hygiene factor

(2) Events as a competitive advantage in place marketing

(3) Events as incubators

(4) Events as social service

(5) The role of intrinsic value

\section{Economic value as a hygiene factor}

Perhaps the most common sentiment that was expressed in the discussion on event value was the idea that events first and foremost should deliver a certain monetary value. Not until this is achieved can the less tangible social values be addressed and enjoyed. One of the organizers (interviewee \#8) stressed how they prioritize the economic aspect of their event as it plays an important role in the planning, execution and continued justification of their event's existence in the eyes of its stakeholders.

Some kind of economic kick-back is important: i.e. what does (the event) contribute to a place? [. . .] In short, what can we contribute economically? It is not until that point that it becomes a matter of those things that do not fit in a spreadsheet.

A destination representative (interviewee \#6) echoed the prioritization of the economic viability of events, but he instead framed it in terms of the potential this provides for tourism development:

From the perspective of my role, which is to develop the tourism industry, we naturally see value as including the ability to attract tourists to the region. [. . . ] if you do manage to attract tourists then they need somewhere to eat, sleep and spend money at-that is also economic value.

In other words, the respondents felt that events should be able to demonstrate economic viability and preferably even be able to provide economic community benefits through external investments, tourism and increased local expenditure. If they are unable to exhibit economic muscle of this sort, then any further municipal support will be hard to justify. Events that are purely based on the expectation of social benefits will struggle to justify their existence when financial support is needed to maintain such an event in the long term.

\section{Events as a competitive advantage in place marketing}

The interviewees frequently singled out events as decisive for the image of a community and, consequently, its attractiveness in the eyes of prospective new residents. A municipal official suggested that events provide Ostersund with a competitive advantage over other, otherwise better-known or larger towns and cities in the Northern parts of Sweden (interviewee \#1):

I think that events and the cultural offer contribute to getting people to move here. [. . . . . . a growing population in turn translates into a lot of money for the place which is the basic function of the societal value of events in my view.

However, there was a distinction made between usefulplace branding events and events that are overrated as place branding tools. The latter type was described as ephemeral events that are 
not connected to any place but rather change venue every time and demand hefty investments from each host community when doing so. For example, the local events champion (interviewee \#4) considered television-based place branding through events to often be overrated in the effect they have on the image of a place.

... (numerous) events are superficially motivated as being good for the brand of the destination, when they are not! For example, who remembers that last week's Musikfestivalen qualification contest took place in Nyköping? That host location was barely evident from the broadcast. [. . .] And yet they spent hundreds of thousands to bid for and host that event in Nyköping, solely based on the idea that it would put that town on the map.

\section{Events as incubators}

It was also suggested that Östersund's flag-bearing hallmark events play an important role as incubators that are able to host and catalyze a variety of projects, ideas, movements and entrepreneurs. Local events were said to provide opportunities to showcase local talents, as is the case with the annual music festival where whole sections of the festival area are devoted to art exhibitions and smaller stages used by local musicians. Other events leave physical infrastructure that can be used members of the community that otherwise lack resources to practice certain activities. This is the case with an annual winter sports event that has an arena equipped with exactly the sorts of facilities needed by both exercise enthusiasts and local youth sports clubs during the rest of the year. The regional DMO representative (interviewee \#6) gave an overview of the different types of incubator-type functions that the local events provide:

... the cross country-skiing and Biathlon arena [...] benefit the community and the destination. Then you have cultural events, such as Storsjoyran music festival. [.. . ] it is underappreciated in terms of what it contributes to the community. It has become somewhat of an incubator for culture stakeholders, and they have had this role for many years now. [...] (the festival) provides a great stage for new and up-and-coming artists to be seen and build their networks.

\section{Events as a social service}

The interviewees did express awareness of the fact that events play an important role as stewards of community welfare in several ways. Events are a distraction and highlight of everyday life for marginalized or underprivileged groups in the community. For example, one organizer expressed the importance of top-tier football matches for older community members (interviewee \#7):

... pensioners often say "what would we do if we did not have the football?" It makes one grateful for being able to provide something that improves their everyday lives so much as to say such a thing.

Not only can events serve as occasions to look forward to, they can be actively designed with such groups in mind (interviewee \#5):

We used to have an event called "locals", where we invited all community residents and even tourists to a locals' day full of activities on the square, in the park etc. [.. . . One easily becomes blind to the fact that some might not be able to afford to do activities, so that prompted us to make this locals day. It had all kinds of activities...

Finally, events can also address certain social issues in a more direct manner. In these cases, however, it is often a case of public funding and is thus steered by the access to funds rather than the possession of innovative event ideas (interviewee \#4):

... societal value can also come in the form of manifestations about social challenges or issues, such as demonstrations about the rights of immigrants, for example. These planned events are often publicly funded, so societal value and the source of funding is quite strongly connected in my view. 
IJEFM

13,2

228

\section{The importance of intrinsic value}

A couple of interviewees complained that other policy stakeholders try to outsource community services by making financial support of events contingent on certain criteria that organizers have to fulfill. The argument held by those defending the independence of events from policy objectives revealed a perspective on value that conformed to neither the traditional sociological nor the economics-based perspectives, but instead revealed a moral stance claiming events to be an inherent public good. This perspective amounts to what might be considered an exceptionalist stance, where expectations on events to achieve deliverables such as economic or social benefits are considered to be unfavorable and unfair. Rather, if events are freed from such burdens, they will be better equipped to actually contribute value to the community.

As one organizer explained, there is growing frustration among some event organizers over pressure to "deliver" benefits to the local community (interviewee \#8):

... another important question is whether cultural events can be inherently valuable or if they "have to" deliver some societal good. In other words, whether it is a matter of cultural politics or a matter of business politics. [...] My opinion is that those who organize events should not feel pressure to put societal value first but rather they should focus on staging a great event.

The organizer essentially suggested that events are creative endeavors and that creativity is hampered when external expectations, such as municipal policy objectives, are imposed on such endeavors. Counterintuitively, this laissez-faire approach to event policy is then thought to contribute with more net value over time after the best possible experience has been delivered to visitors and community residents. The full potential of an event risks not being realized if hard tourism- and economically related metrics are demanded of them, especially in the formative phases of the event. The local hallmark music festival might not have become what it is today, had financial support when it started been based on its potential back then to draw tourists, for example, as told by its organizer (interviewee \#3):

... when we started our music festival a long time ago, then the local government and people in general said that we were more than welcome to stage the event but that we absolutely cannot collide with the high-profile hallmark event of Östersund at the time called "Expo Norr". Now that event is a footnote in comparison to our event. But back then it was hard for local civil servants and politicians to be able to predict the ripple effect we would have and determine that we could contribute with such societal utility. If they back then had calculated the amount of expected guest nights and figures of this sort then our event would likely not have looked like such a great proposition ...

\section{Discussion}

Perhaps not surprisingly, the interviewees by and large projected a view on value that centered on events as products that are consumed in a system of economic exchanges. This means that their answers mainly focused on ways that events contribute to community revenue: either directly by means of the organizers paying tax and of visitors spending money in the local community or indirectly, by first by enhancing the image of the place to increase long-term tourism and in-migration (Dwyer and Forsyth, 2017). The long-term line of reasoning applies to the respondents that suggested that cultural events should be freed from the burden of deliverables when they apply for funding because the net economic benefit over time likely is higher if event organizers are left alone. It does not, however, give any particular priority to social benefit over economic once an event has been staged. Moreover, social benefits were often explained in economic terms by the respondents, where community residents, through their consumption of events (where the cost is tax and efforts related to attendance), were said to be able to gain access to social benefits. 
In fact, very little attention at all was paid to social benefits as the end game of why communities should host events. Social benefits were instead seen as a segue to economic benefits. Economic benefits were portrayed as a hygiene requirement that should be met to in order to justify the existence of events. Hence, if events cannot prove their economic mettle, then any discussion of social benefit is futile. The respondents' general views correspond to Djaballah et al.'s (2015) observation that there is a tendency by local governments and organizers to disregard noneconomic outcomes and leveraging opportunities in the process of planning and managing event portfolios. This approach of prioritizing certain values as being more crucial than others suggests an inclination for policy stakeholders to apply a multifactor logic when assessing and making event-related decisions, a logic that follows the theories originating with Herzberg (1959), Kano et al., (1984) and Crompton (2003), among others. The prioritizations made by policy stakeholders could partly be explained by the fact that community residents tend to appraise public policy based on points of dissatisfaction instead of services that they are satisfied with (Holian, 2011). Addressing perceived hygiene factors such as tourism revenue is a way of mitigating dissatisfaction and thereby appeasing constituents, especially in the case of policy stakeholders directly dependent on political popularity.

Although events in some cases were argued to fill the role of a social service, this was a role exclusively attributed to publicly organized events as they were said to not have the same pressure that privately organized events have to display economic viability and perhaps more importantly, are often designed exclusively with social benefit and the public good in mind, a fact supported by Wood $(2005,2006,2008)$ as well as Carlsen and Andersson (2011). By contrast, although private sector events do occasionally produce outcomes that can be considered to be of social benefit, the majority are driven by a need to produce a return on investment measured in economic rather than social terms (Carlsen and Andersson, 2011).

Perhaps the most telling sign of the ruling econocentrism in the events sector came when interviewees framed the sector as a market where events compete against each other for visitors or funds or brand awareness. Not only was a market logic apparent on the level of events but also on the level of competing destinations where events can consolidate the destination brand and act as catalysts for growth, as also described by Getz (2004). Based on the role of policy stakeholders in the evaluation of events, it is likely that the econocentrism and market logic held by policy stakeholders go on to permeate public discourse as events are championed with such logic in mind.

Whereas the Intrinsic-Extrinsic and Individual-Society axes provide some insight into dimensions that comprise value in an events context (Lundberg et al., 2017), they omit the process by which value is eventually interpreted and acted upon and how this process differs between different types of stakeholders (Getz and Page, 2016). The inseparability of the evaluator and target audience from the evaluative criteria is an important aspect that warrants attention in the study of event value. In other words, those who commission and those who make decisions based on evaluations should be accounted for based on their agendas, the context they operate in and the assumptions that underlie their interpretation of value.

The event value framework by Lundberg et al. (2017) could be developed by acknowledging the critical role of policy stakeholders who commission, interpret and make critical decisions based on event assessments and evaluations. The amendment presented here aims to demonstrate how these stakeholders help to consolidate how the value of events is perceived in society. Figure 2 suggests a dynamic for how policy stakeholders relate to and help to shape how event value is constructed in political and subsequently public discourse, which then feeds back into the frame of reference that policy stakeholders operate within. stakeholders' perceptions of event value

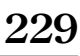




\section{IJEFM 13,2}

Figure 2.

An amended event value framework for evaluation and policy contexts, adapted from "A four-dimensional approach to event values"

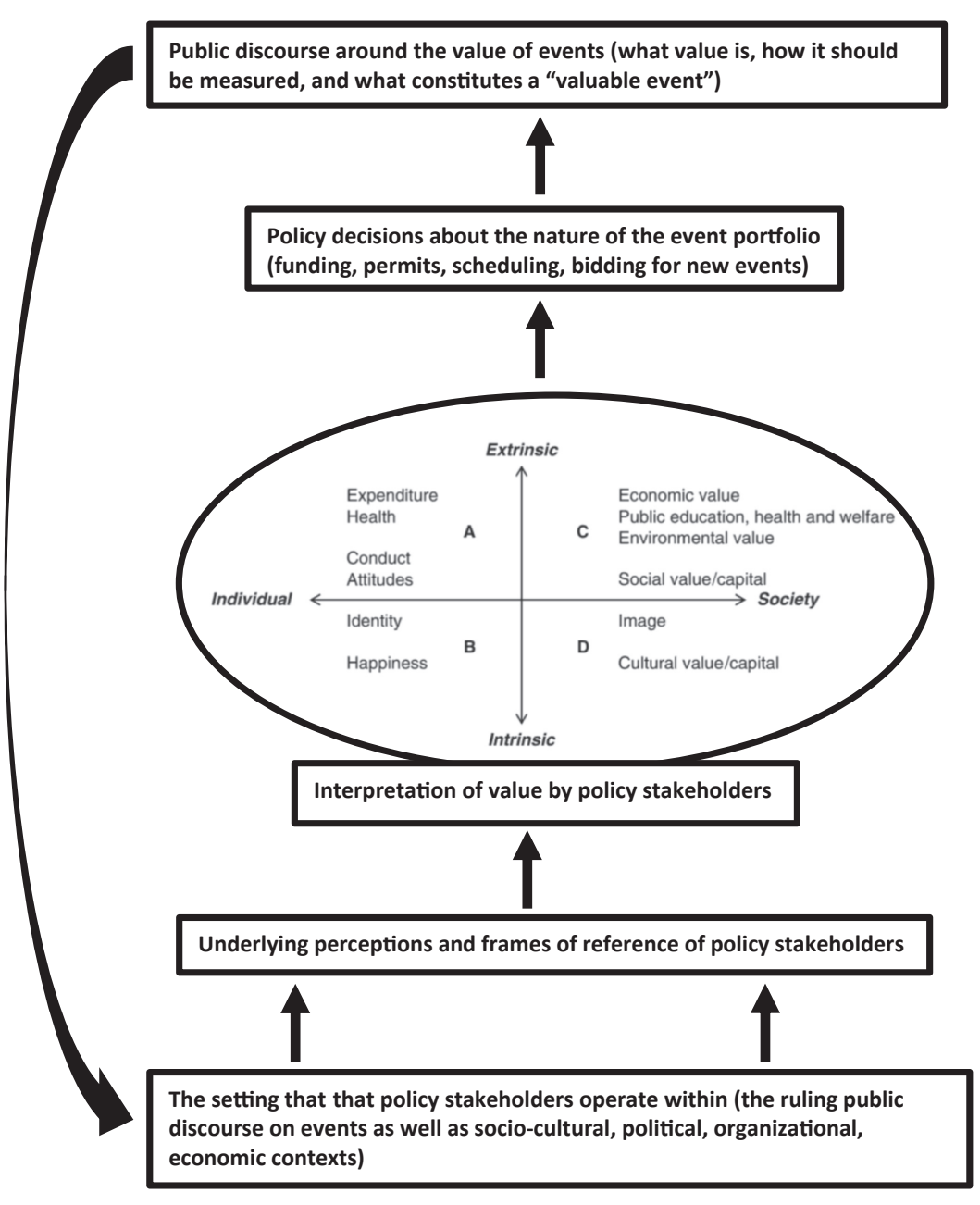

Source(s): Lundberg et al. (2017)

\section{Conclusion}

Although the paper sets out to explore policy stakeholders' views, it does so through the lens of one specific location. As such, caution should be taken when generalizing the dynamics found in this study to other contexts. More research needs to be done to establish whether the same tendencies exist in other destinations in Sweden, other Western European settings and beyond. The study also did not ask the respondents about their own perspectives on their role in the discourse on event value, but rather inferences were made based on stakeholder and events literature. This was done in a bid to avoid bias by, for example, respondents downplaying their role in shaping the discourse on event value. It also means that the respondents were not able to reflect on this exact point. Future studies could adopt a research design that allows for reflexivity to identify any gaps between the policy stakeholders' subjective view of their role and the patterns observable in stakeholder dependencies (Getz and Andersson, 2010). 
The views on value revealed here are in line with prevailing event assessment and evaluation methodologies. The self-reinforcing relationship between policy stakeholders and evaluation praxis in industry and academia means that those in power over event policy can refer to state-of-the-art research to consolidate their view on event value. Furthermore, evaluation is easier to conduct when the involved stakeholders understand and are themselves interested in the types of values measured. As a result, the status quo is likely to remain for some time as the inclusive, multidimensional and multistakeholder approach advocated by some researchers (Moscardo, 2007; Brown et al., 2015; Getz and Page, 2016; Getz et al., 2017; Sadd et al., 2017) will be difficult to achieve on any significant scale as long as these feedback loops exist. More research is also needed on how event evaluations could be standardized and be made more accessible (i.e. digestible) for policymakers and the general public.

\section{References}

Andersson, T. and Armbrecht, J. (2014), "Factors explaining the use-value of sport event experiences", International Journal of Event and Festival Management, Vol. 5 No. 3, pp. 235-246.

Andersson, T., Armbrecht, J. and Lundberg, E. (2017a), "The use and non-use valued of events", in Lundberg, E., Armbrecht, J., Andersson, T. and Getz, D. (Eds), The Value of Events, Routledge, London, pp. 105-123.

Andersson, T., Armbrecht, J. and Lundberg, E. (2017b), "Linking event quality to economic impact", Journal of Vacation Marketing, Vol. 23 No. 2, pp. 114-132.

Andrews, T. (2012), "What is social constructionism?", The Grounded Theory Review, Vol. 11 No. 1, pp. 39-46.

Arcodia, C. and Whitford, M. (2007), "Festival attendance and the development of social capital", Journal of Convention and Event Tourism, Vol. 8 No. 2, pp. 1-18.

Armstrong, G., Hobbs, D., Lindsay, I., Giulianotti, R. and Klauser, F. (2011), "Calling the shots: the pre2012 London olympic contest", Urban Studies (Edinburgh, Scotland), Vol. 48 No. 15, pp. 3169-3184.

Bourdieu, P. (1986), "The forms of capital”, in Richardson, J.G. (Ed.), Handbook of Theory and Research for the Sociology of Education, Greenwood Press, New York, pp. 241-258.

Braun, V. and Clarke, V. (2006), "Using thematic analysis in psychology", Qualitative Research in Psychology, Vol. 3, pp. 77-101.

Brown, S., Getz, D., Pettersson, R. and Wallstam, M. (2015), "Event evaluation: definitions, concepts and a state-of-the-art review", International Journal of Event and Festival Management, Vol. 6 No. 2, pp. 135-157.

Carlsen, J. and Andersson, T. (2011), "Strategic SWOT analysis of public, private and not-for-profit festival organisations", International Journal of Event and Festival Management, Vol. 2 No. 1, pp. 83-97.

Chalip, L. (2004), "Beyond impact: a general model for sport event leverage", in Ritchie, B.W. and Adair, D. (Eds), Sport Tourism: Interrelationships, Impacts and Issues, Clevedon, Channel View Publications, pp. 226-252.

Chalip, L. (2006), "Towards social leverage of sport events", Journal of Sport and Tourism, Vol. 11 No. 2, pp. 109-127.

Crespi-Vallbona, M. and Richards, G. (2007), "The meaning of cultural festivals", International Journal of Cultural Policy, Vol. 13 No. 1, pp. 103-122.

Crompton, J. (2003), "Adapting Herzberg: a conceptualization of the effects of hygiene and motivator attributes on perceptions of event quality", Journal of Travel Research, Vol. 41 No. 3, pp. 305-310.

Crotty, M. (1998), The Foundations of Social Research, Allen \& Unwin, Sydney. stakeholders'

perceptions of event value 
IJEFM 13,2

Davies, L., Coleman, R. and Ramchandani, G. (2013), "Evaluating event economic impact: rigour versus reality?", International Journal of Event and Festival Management, Vol. 4 No. 1, pp. 31-42.

Deane, P. (1978), The Evolution of Economic Ideas, Cambridge University Press, Cambridge.

Delgado, M. (2017), Celebrating Urban Community Life: Fairs, Festivals, Parades, and Community Practice, University of Toronto Press, Toronto.

Djaballah, M., Hautbois, C. and Desbordes, M. (2015), "Non-mega sporting events' social impacts: a sensemaking approach of local governments' perceptions and strategies”, European Sport Management Quarterly, Vol. 15 No. 1, pp. 48-76.

Dobson, S. and Goddard, J. (2011), "The economics of the world cup”, in Dobson, S. and Goddard (Eds), The Economics of Football, Cambridge, Cambridge University Press, pp. 405-422.

Dwyer, L. and Forsyth, P. (2017), "Event evaluation: approaches and new challenges", in Lundberg, E., Armbrecht, J., Andersson, T. and Getz, D. (Eds), The Value of Events, Routledge, London, pp. 105-123.

Dwyer, L., Forsyth, P., Madden, J. and Spurr, R. (2000), "Economic impacts of inbound tourism under different assumptions regarding the macroeconomy", Current Issues in Tourism, Vol. 3 No. 4, pp. 325-363.

Filia, K., Jackson, H., Cotton, S., Gardner, A. and Killackey, E. (2018), "What is social inclusion? A thematic analysis of professional opinion", Psychiatric Rehabilitation Journal, Vol. 41 No. 3, pp. 183-195.

Getz (2004), "Bidding on events", Journal of Convention and Exhibition Management, Vol. 5 No. 2, pp. 1-24.

Getz, D. (2018), Event Evaluation: Theory and Methods for Event Management and Tourism, Goodfellow Publishers, Oxford.

Getz, D. and Andersson, T. (2010), "Festival stakeholders: exploring relationships and dependency through a four-country comparison", Journal of Hospitality and Tourism Research, Vol. 34 No. 4, pp. 531-556.

Getz, D. and Page, S. (2016), "Progress and prospects for event tourism research", Tourism Management, Vol. 52, pp. 593-631.

Getz, D., Andersson, T., Armbrecht, J. and Lundberg, E. (2017), "A synthesis, summaries, and some ontological propositions", in Lundberg, E., Armbrecht, J., Andersson, T. and Getz, D. (Eds), The Value of Events, Oxon, Routledge, pp. 181-199.

Goldblatt, J. (2011), Special Events, 6th ed., Wiley, New York, NY.

Hart, S. (1971), "Axiology-theory of values", Philosophy and Phenomenological Research, Vol. 32 No. 1, pp. 29-41.

Herzberg, F. (1959), The Motivation to Work, Wiley, New Jersey.

Holbrook, M. and Corfman, K. (1985), "Quality and value in the consumption experience: phaedrus rides again”, Jacoby, J. and Olson, J. (Eds), Lexington, Perceived Quality, MA, Lexington Books, pp. 31-57.

Holian, M. (2011), "Homeownership, dissatisfaction and voting", Journal of Housing Economics, Vol. 20, pp. 267-275.

Jamieson, N. (2014), "Sport tourism events as community builders: how social capital helps the 'locals", Cope Journal of Convention and Event Tourism, Vol. 15 No. 1, pp. 57-68.

JHT (2021), "Fakta och statistic", available at: https://jht.se/fakta-statistik/ (accessed 28 September 2021).

Jones, Z. and Ponzini, D. (2020), "Umbrellas, incubators, mothers, and killers: four types of relationship between cultural mega-events and small and micro events in heritage-rich European cities", in Di Vita, S. and Wilson, M. (Eds), Planning and Managing Smaller Events: Downsizing the Urban Spectacle, Routledge, London, Ch.3. 
Kano, N., Seraku, N., Takahashi, F. and Tsjui, S. (1984), "Attractive quality and must-be quality", Hinshitsu, Vol. 14 No. 2, pp. 147-156.

Kisida, B., Greene, J. and Bowen, D. (2014), "Creating cultural consumers: the dynamics of cultural capital acquisition”, Sociology of Education, Vol. 87 No. 4, pp. 281-295.

Kwiatkowski, G. (2016), "Economic impact of event attendees' spending on a host region: a review of the research", Event Management, Vol. 20 No. 4, pp. 501-515.

Lundberg, E., Armbrecht, J., Andersson, T. and Getz, D. (Eds) (2017), The Value of Events, Oxon, Routledge.

McFee, G. (2012), “Olympism and sport's intrinsic value”, Sport, Ethics and Philosophy, Vol. 6 No. 2, pp. 211-231.

Martensen, A. and Grønholdt, L. (2008), "How events work: understanding consumer responses to event marketing", Innovative Marketing, Vol. 4 No. 4, pp. 44-56.

Mitchell, R., Agle, B. and Wood, D. (1997), "Towards a theory of stakeholder identification and salience: defining the principle of who and what really counts", Academy of Management Review, Vol. 22 No. 4, pp. 853-886.

Molitor, F., Rossi, M., Branton, L. and Field, J. (2011), "Increasing social capital and personal efficacy through small-scale community events", Journal of Community Psychology, Vol. 39 No. 6, pp. 749-754.

Moscardo, G. (2007), "Analyzing the role of festivals and events in regional development", Event Management, Vol. 11 No. 1, pp. 23-32.

Ostersundspulsen (2021), "Vad vill du berätta om Östersund?", available at: https://ostersundspulsen.se/ (accessed 22 September 2021).

O'Sullivan, D., Pickernell, D. and Senyard, J. (2009), "Public sector evaluation of festivals and special events", Journal of Policy Research in Tourism, Leisure and Events, Vol. 1 No. 1, pp. 19-36.

Palinkas, A., Horwitz, S., Green, C., Wisdom, J., Duan, N. and Hoagwood, K. (2015), "Purposeful sampling for qualitative data collection and analysis in mixed methods implementation research", Administrative Policy Mental Health, Vol. 42 No. 5, pp. 533-544.

Portes, A. (1998), "Social capital: its origins and applications in modern sociology", Annual Review of Sociology, Vol. 24 No. 1, pp. 1-24.

Reid, S. (2006), "Identifying social consequences of rural events", Event Management, Vol. 11 No. 1, pp. 89-98.

Richards, G. (2017), "From place branding to placemaking: the role of events", International Journal of Event and Festival Management, Vol. 8 No. 1, pp. 8-23.

Rogerson, R., Nicholson, R., Reid, F. and Sly, B. (2019), "Using major events to increase social connections: the case of the Glasgow 2014 Host City volunteer programme", Journal of Policy Research in Tourism, Leisure and Events, Vol. 13 No. 1, pp. 1-13.

Sadd, D., Fyall, A. and Wardrop, K. (2017), "Evaluative event frameworks: a learning destination perspective", International Journal of Tourism Research, Vol. 19 No. 3, pp. 339-348.

Saunders, B., Kitzinger, J. and Kitzinger, C. (2015), "Anonymising interview data: challenges and compromise in practice", Qualitative Research, Vol. 15 No. 5, pp. 616-632.

Sharpley, R. and Stone, P. (2012), "Socio-cultural impacts of events: meanings, authorised transgression and social capital" Page, S. and Connell, J. (Eds), The Routledge Handbook of Events, London, Routledge, pp. 347-361.

Sherry, E., Karg, A. and O’May, F. (2011), "Social capital and sport events: spectator attitudinal change and the Homeless World Cup", Sport in Society, Vol. 14 No. 1, pp. 111-125.

Silverman, D. (2010), Doing Qualitative Research, 3rd ed., Sage Publications, Thousand Oaks, CA.

Strauss, A. and Corbin, J.M. (1997), Grounded Theory in Practice, Sage, London. stakeholders'

perceptions of

event value

233 
IJEFM 13,2

Sundbo, J. (2004), "The management of rock festivals as a basis for business-dynamics: an example of the growing experience economy", International Journal of Entrepreneurship and Innovation Management, Vol. 4 No. 6, pp. 587-612.

Todd, L., Leask, A. and Ensor, J. (2017), 'Understanding primary stakeholders' multiple roles in hallmark event tourism management”, Tourism Management (1982), Vol. 59, pp. 494-509.

Van Niekerk, M. (2016), "The applicability and usefulness of the stakeholder strategy matrix for festival management”, Event Management, Vol. 20 No. 2, pp. 165-179.

Van Niekerk, M. and Getz, D. (2019), Event Stakeholders, Goodfellow, Oxford.

Vargo, S. and Lusch, R. (2004), "Evolving to a new dominant logic for marketing", Journal of Marketing, Vol. 68 No. 1, pp. 1-17.

Wallstam, M., Ioannides, D. and Pettersson, R. (2018), "Evaluating the social impacts of events: in search of unified indicators for effective policymaking", Journal of Policy Research in Tourism, Leisure and Events, Vol. 12 No. 2, pp. 122-141.

Wood, E. (2005), "Measuring the economic and social impacts of local authority events", The International Journal of Public Sector Management, Vol. 18 No. 1, pp. 37-53.

Wood, E. (2006), "Measuring the social impacts of local authority events: a pilot study for a civic pride scale", International Journal of Nonprofit and Voluntary Sector Marketing, Vol. 11 No. 3, pp. 165-179.

Wood, E. (2008), “An impact evaluation framework: local government community festivals”, Event Management, Vol. 12 No. 3, pp. 171-185.

Zeithaml, V. (1988), "Consumer perceptions of price, quality, and value: a means-end model and synthesis of evidence", Journal of Marketing, Vol. 52 No. 3, pp. 2-22.

Ziakas, V. and Getz, D. (2020), "Shaping the event portfolio management field: premises and integration", International Journal of Contemporary Hospitality Management, Vol. 32 No. 11, pp. 3523-3544.

Zimbalist, A. (2010), "Is it worth it? Hosting the Olympic games and other mega sporting events is an honor many countries aspire to-but why?”, Finance and Development, Vol. 47 No. 1, pp. 8-11.

Ziółkowska, J. (2020), "Enhancing social capital development throughout cultural events: a case study of Eastern Poland”, Geo Journal of Tourism and Geosites, Vol. 29 No. 2, pp. 450-459.

\section{Corresponding author}

Martin Wallstam can be contacted at: martin.wallstam@miun.se

For instructions on how to order reprints of this article, please visit our website:

www.emeraldgrouppublishing.com/licensing/reprints.htm

Or contact us for further details: permissions@emeraldinsight.com 